\title{
Minimally Invasive Treatment of Patients with Acute Appendicitis
}

\author{
Alexei L. Charyshkin, PhD, ScD*; Maksim M. Yartsev; Oleg V. Midlenko, PhD, ScD; \\ Antonina V. Smolkina, PhD, ScD; Nikolai I. Belonogov, PhD, ScD \\ Institute of Medicine, Ecology and Physical Education of Ulyanovsk State University \\ Ulyanovsk, the Russian Federation
}

\begin{abstract}
The aim of our study was to improve the surgical treatment of patients with acute appendicitis (AA) by improving the miniincision approach.

Materials and Methods: The study included 220 patients (mean age of 38.9 \pm 14.3 years) with AA, who underwent surgical treatment in the period from 2008 to 2017. A mini-incision appendectomy was performed on all patients. Patients were divided into 2 groups. The groups were comparable with respect to age and sex. Group 1 included 140 patients who underwent appendectomy by the traditional method of minilaparotomy with the classical sanitation and drainage of the abdominal cavity. Group 2 included 80 patients who underwent appendectomy by the developed method of a minimally invasive approach and sanitation and drainage of the abdominal cavity.

Results: The developed method of minilaparotomy expands and improves the area of accessibility by an average of $4.8 \mathrm{~cm}^{2}$ for surgical manipulations during an appendectomy. The proposed method of minilaparotomy reduces the duration of an appendectomy by an average of 11.5 minutes, and the rate of complications during surgery and purulent-inflammatory complications by $3.9 \%$. (International Journal of Biomedicine. 2019;9(2):131-133.)
\end{abstract}

Key Words: acute appendicitis $\bullet$ appendectomy $\bullet$ minilaparotomy $\bullet$ complications

\section{Introduction}

Minimally invasive surgical interventions are designed to reduce the trauma of surgery and the duration of hospitalization and rehabilitation of patients, and to improve the cosmetic effect. ${ }^{(1-5)}$ In patients with acute appendicitis (AA) and the presence of such complications as typhlitis, abscesses or atypical location of the appendix, the performance of a minilaparotomy is preferable to video laparoscopy. Appendectomy using minilaparotomy in patients with subhepatic location of the appendix is difficult to perform; these cases are often converted to laparotomy. ${ }^{(6-9)}$

Mini-incision surgery in certain situations has significant advantages over laparotomy and, in some cases, over video laparoscopy. ${ }^{(1-6)}$ We believe that the optimization of abdominal mini-incision surgery is an urgent task at the present stage of development of minimally invasive technologies.

*Corresponding author: Prof. Alexei L. Charyshkin, PhD, $S c D$, Head of the Faculty Surgery Department, Institute of Medicine, Ecology and Physical Education, Ulyanovsk State University. Ulyanovsk, the Russian Federation.E-mail: charyshkin@yandex.ru
The aim of our study was to improve the surgical treatment of patients with AA by improving the mini-incision approach.

\section{Materials and Methods}

The study included 220 patients (mean age of $38.9 \pm 14.3$ years) with AA, who underwent surgical treatment in Ulyanovsk Regional Clinical Center for Specialized Types of Medical Aid and the surgical department at the Nikolaev district hospital of the Ulyanovsk region in the period from 2008 to 2017.

The study was conducted in accordance with ethical principles of the Declaration of Helsinki and approved by the by Ethics Committees at our institutions. All patients underwent general clinical and laboratory, radiographic, endoscopic, ultrasound, histological methods of investigation. A mini-incision appendectomy was performed on all patients. Patients were divided into 2 groups. The groups were comparable with respect to age and sex. Group 1 included 140 patients who underwent appendectomy by the traditional method of minilaparotomy with the classical sanitation and 
drainage of the abdominal cavity. Group 2 included 80 patients who underwent appendectomy by the developed method of a minimally invasive approach and sanitation and drainage of the abdominal cavity. ${ }^{(6,10)}$

In the postoperative period, adequate infusion therapy was performed. To prevent purulent complications, cephalosporins of the third generation were intravenously prescribed.

To assess the proposed method of minilaparotomy, we measured the area of accessibility during the operation in both groups. ${ }^{(1,2)}$ Leukocyte index of intoxication (LII) was calculated by the formula of V.K. Ostrovsky. ${ }^{(11)}$

Statistical analysis was performed using the statistical software «Statistica» (v6.0, StatSoft, USA). All values are presented as mean $\pm \mathrm{SEM}$ ). The inter-group comparisons were performed using Student's t-test. A probability value of $P<0.05$ was considered statistically significant.

\section{Results and Discussion}

The age and sex distribution of patients is shown in Table 1. There were 92(41.8\%) men and $128(58.2 \%)$ women. The working-age patients were predominant $(96.6 \%)$. Twelve (5.4\%) patients were over 60 years old. In Group 1, the rate of conversion to laparotomy was $17.1 \%$. Table 2 lists the reasons for the conversion. In Group 2, there were no conversions to laparotomy.

Table 1.

The age and sex distribution of $A A$ patients

\begin{tabular}{|c|c|c|c|}
\hline \multirow{2}{*}{$\begin{array}{c}\text { Age } \\
\text { (year) }\end{array}$} & \multicolumn{2}{|c|}{ Sex } & \multirow{2}{*}{$\mathrm{n} / \%$} \\
\cline { 2 - 3 } & Men & Women & \\
\hline $18-29$ & 52 & 54 & $106 / 48.2$ \\
\hline $30-39$ & 18 & 29 & $47 / 21.4$ \\
\hline $40-49$ & 12 & 28 & $40 / 18.2$ \\
\hline $50-59$ & 3 & 12 & $15 / 6.8$ \\
\hline $60-69$ & 3 & 3 & $6 / 2.7$ \\
\hline$\geq 70$ & 4 & 2 & $6 / 2.7$ \\
\hline Total: & $92 / 41.8$ & $128 / 58.2$ & $220 / 100$ \\
\hline
\end{tabular}

Table 2.

The reasons for the conversion to laparotomy in Group 1.

\begin{tabular}{|l|c|}
\hline \multicolumn{1}{|c|}{ Reasons } & $\mathrm{n} / \%$ \\
\hline $\begin{array}{l}\text { Loose appendicular infiltrate, } \\
\text { difficulty in identifying the appendix }\end{array}$ & $6 / 4.3$ \\
\hline $\begin{array}{l}\text { Limited availability (subhepatic or } \\
\text { pelvic location of the appendix) }\end{array}$ & $18 / 12.8$ \\
\hline Total & $24 / 17.1$ \\
\hline
\end{tabular}

The area of accessibility was $13.1 \pm 1.1 \mathrm{~cm}^{2}$ in Group 1 and $17.9 \pm 1.2 \mathrm{~cm}^{2}$ in Group $2(P<0.05)$. On the fourth day after the appendectomy, the LII was 5.7 \pm 0.1 in Group 1 and $3.2 \pm 0.2$ in Group 2. During the other days, the LII decreased equally. The wounds were fully healed within $8.1 \pm 0.2$ days and $6.0 \pm 0.1$ days after surgery in Group 1 and Group 2, respectively, which was significantly shorter by 2 days in Group $2(P<0.05)$.

The duration of the appendectomy was $29.7 \pm 10.1$ minutes in Group 1 and 18.2 \pm 11.1 minutes in Group 2, which reduced the time of surgery by 11.5 minutes in Group 2 $(P<0.05)$. The intraoperative bleeding from a. appendicularis was detected in $8(5.7 \%)$ patients of Group 1 and $1(1.25 \%)$ patient of Group 2. An injury to the dome of the cecum (damage of serous membrane, wall hematoma) was observed only in Group 1 in 6(4.3\%) patients.

Thus, the proposed method of minilaparotomy contributes to reducing the number of complications during surgery. We believe that the reduction of complications in Group 2 is associated with the original mini-access, which contributed to the increase and improvement of the area of accessibility for surgical manipulations during appendectomy.

Purulent-inflammatory complications were detected in 9(6.4\%) patients of Group 1 and 2(2.5\%) of Group 2.

Performing an appendectomy with the developed mini-incision contributes to reducing the traumatic impact of retractors on the skin, subcutaneous tissue, and muscle layer, as well as anoneurosis of the anterior abdominal wall in the surgical area, which eliminates tissue ischemia, thereby significantly reducing the number of inflammatory complications of the wound.

\section{Findings}

1. Conversion to laparotomy during the traditional method of minilaparotomy is $17.1 \%$ of cases; the main indication for conversion (up to 12.8\%) is the limited availability of the appendix with a subhepatic and pelvic location.

2. The developed method of minilaparotomy expands and improves the area of accessibility by an average of $4.8 \mathrm{~cm}^{2}$ for surgical manipulations during an appendectomy.

3. The proposed method of minilaparotomy reduces the duration of an appendectomy by an average of 11.5 minutes, and the rate of complications during surgery and purulentinflammatory complications by $3.9 \%$.

\section{Competing Interests} interests.

The authors declare that they have no competing

\section{Sources of Funding}

This study was funded by the Ministry of Education and Science of the Russian Federation (the science project No. 18.7236.2017/BCh).

\section{References}

1. Beburshvili AG, Mikhin SV. Operations from the open small access combined with other minimally invasive 
technologies. Mini-access surgery. Yekaterinburg, 2005:111112.[in Russian].

2. Prudkov MI. Basics of minimally invasive surgery. Yekaterinburg: Publishing House of the Ural State University; 2007. [in Russian].

3. Remizov OV, Maskin SS, Karsanov AM, Vakhotskiy VV, Gudushauri MK. Possibility of radiation imaging in acute appendicitis. Medical News of the North Caucasus. 2017;12(1):105-110. doi: 10.14300/mnnc.2017.12031

4. Charyshkin AL, Yakovlev SA. [Preperitoneal blockade in prevention of postoperative complications at patients with appendicular peritonitis]. Modern problems of science and education. 2014;(1). Available from: https://www.scienceeducation.ru/en/article/view?id=12261. [Article in Russian]. 5. Charyshkin AL, Bikbaeva KI. [Comparative results of application of the minilaparotomy at patients with sharp cholecystitis]. Modern problems of science and education. 2014;(2). Available from: https://science-education.ru/en/ article/view?id=12262. [Article in Russian].

6. Charyshkin AL, Yartsev MM. The assessment of quality of life in patients with acute appendicitis after a minimally invasive approach.International JournalofBiomedicine.2018;8(2):139-141. doi: 10.21103/Article8(2)_OA6

7. Rickert A, Bönninghoff R, Post S, Walz M, Runkel N, Kienle P. Appendix stump closure with titanium clips in laparoscopic appendectomy. Langenbecks Arch Surg. 2012;397(2):327-31. doi: 10.1007/s00423-011-0869-5.

8. Suh YJ, Jeong SY, Park KJ, Park JG, Kang SB, Kim DW, et al. Comparison of surgical-site infection between open and laparoscopic appendectomy. J Korean Surg Soc. 2012;82(1):35-9. doi: 10.4174/jkss.2012.82.1.35.

9. Lim SG, Ahn EJ, Kim SY, Chung IY, Park JM, Park SH, Choi KW. A Clinical Comparison of Laparoscopic versus Open Appendectomy for Complicated Appendicitis. J Korean Soc Coloproctol. 2011;27(6):293-7. doi: 10.3393/ jksc.2011.27.6.293.

10. Charyshkin AL, Yartsev MM. Patent of the Russian Federation, "A Method of a minimally invasive approach for appendectomy". (RU \#2612983; priority of 05.11.2016, register. of 03.14.2017; Bull \#8). [in Russian]

11. Ostrovskiĭ VK, Alimov RR, Mashchenko AV, Semenova OP, Kurapova MI. [Normal parameters of leukocytic index of intoxication]. Klin Lab Diagn. 2003;(1):45-6. [Article in Russian]. 